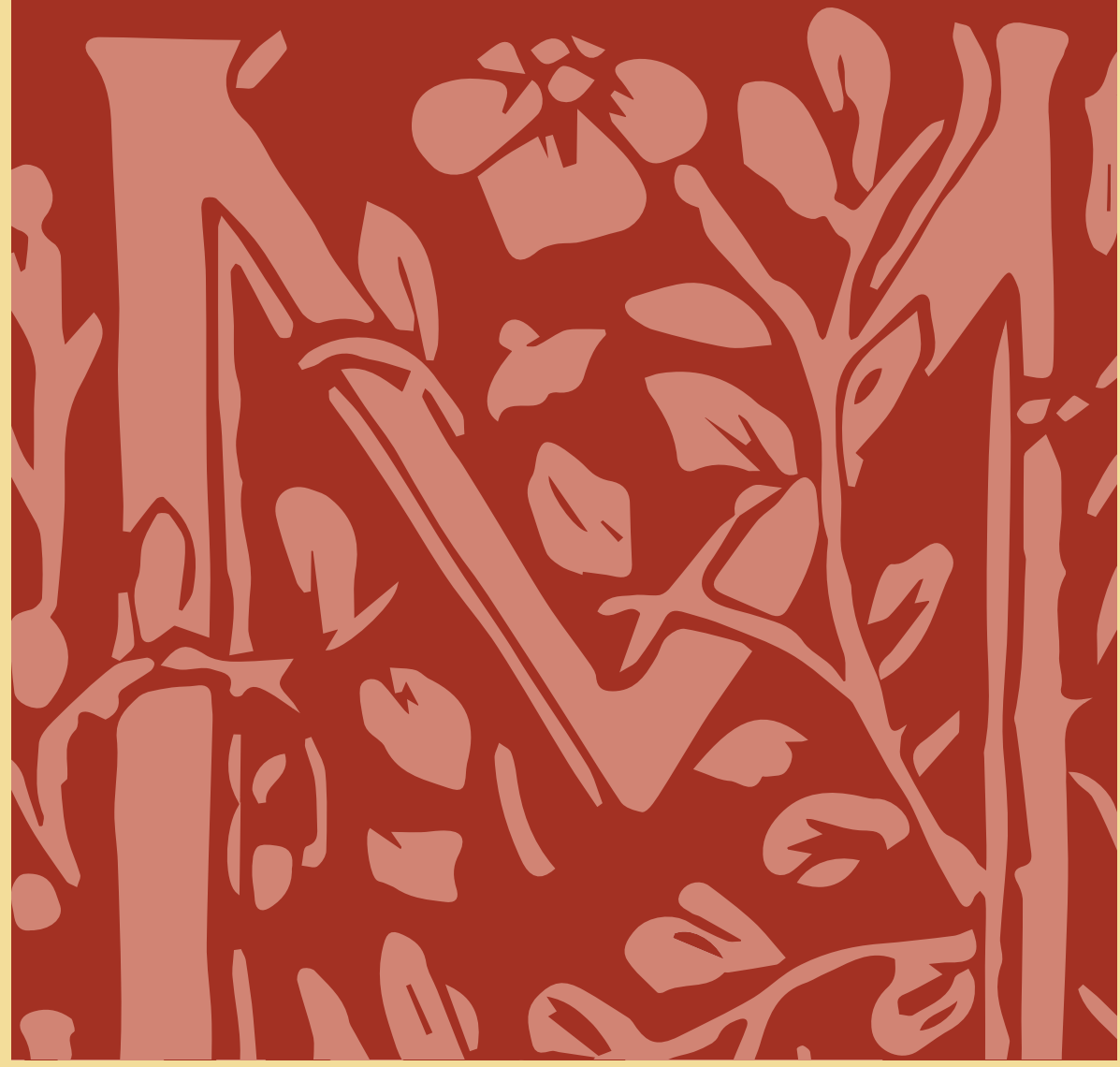

La mujer, protagonista del teatro español del Siglo de Oro

XLIII Jornadas de teatro clásico

Almagro, 14, 15 y 16 de julio de 2020

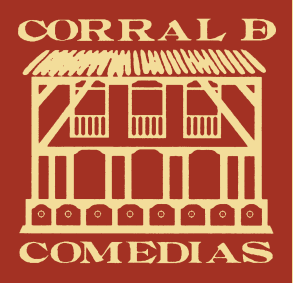

Edición cuidada por

Rafael González Cañal y Almudena García González 


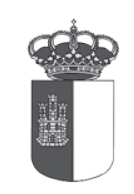

\section{CoRTeS DE}

\section{Castillia-La Mancha}

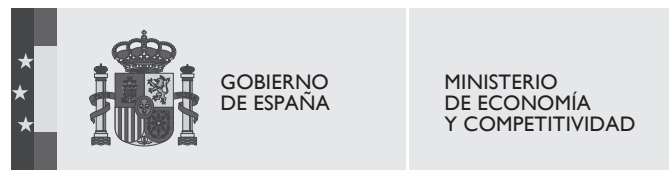

FFI2017-87523-P

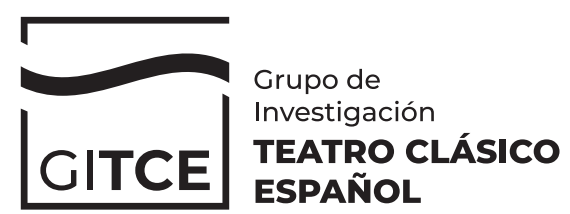

Universidad de Castilla-La Mancha

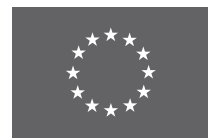

Unión Europea

Fondo Social Europeo 


\title{
La mujer, protagonista del teatro español del Siglo de Oro
}

\author{
XLIII Jornadas de teatro clásico
}

Almagro, 14, 15 y 16 de julio de 2020

Edición cuidada por

Rafael González Cañal

y

Ediciones de la Universidad

2021 


\section{JORNADAS DE TEATRO CLÁSICO DE ALMAGRO}

(43․ 2020. Almagro)

La mujer, protagonista del teatro espańol de Siglo de Oro: XLIII jornadas de teatro clásico, Almagro, 14, 15 y 16 de julio de 2020 / edición cuidada por Rafael González Cañal y Almudena García González.- [Cuenca] : Ediciones de la Universidad de Castilla-La Mancha, 2021.

296 p.; $24 \mathrm{~cm}$.- (Corral de comedias ; 46)

ISBN: 978-84-9044-487-0

1. Teatro español - S. XVII - Historia y crítica I. González Cañal, Rafael, ed. lit. II. García González, Almudena, ed. lit. III. Universidad de Castilla-La Mancha, ed. V. Título VI. Serie

821.134.2-2.09 “16”(063)

(C) de los textos: sus autores.

(C) de la edición: Universidad de Castilla-La Mancha.

Edita: Servicio de Publicaciones de la Universidad de Castilla-La Mancha.

Director: César Sánchez Ortiz.

Colección CORRAL DE COMEDIAS, núm. 46.

Director: Felipe B. Pedraza Jiménez.

$1^{\text {a }}$ ed. Tirada: 200 ejemplares.

Diseño de la cubierta: C.I.D.I (Universidad de Castilla-La Mancha)

Composición y maquetación: Añil desarrollo gráfico -anil.es-

Impresión: MG Color

Impreso en Espańa (U.E.) - Printed in Spain (U.E.)

ISBN: 978-84-9044-487-0 (edición impresa)

D.L. CU 167-2021

ISBN: 978-84-9044-488-7 (edición electrónica)

ISSN: $1699-8650$

Doi: http://doi.org/10.18239/cor_46.2021.00

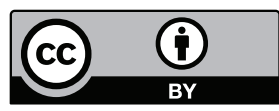

Esta obra se encuentra bajo una licencia internacional Creative Commons CC BY 4.0.

Cualquier forma de reproducción, distribución, comunicación pública o transformación de esta obra no incluida en la licencia Creative Commons CC BY 4.0 solo puede ser realizada con la autorización expresa de los titulares, salvo excepción prevista por la ley. Puede Vd. acceder al texto completo de la licencia en este enlace: https://creativecommons.org/licenses/by/4.0/deed.es 
Rafael González Cañal

Palabras preliminares

Programa

\section{Protagonistas y personajes femeninos}

Rosa Navarro Durán

Discursos «feministas» en boca de damas de comedias de Tirso de Molina

Esther Borrego

Inocente y calumniada. Lucinda perseguida y otras damas lopescas

Marco Presotto

Sonetos de mujeres en el teatro de Lope

Roberta Alviti

«Por los ojos vierto el alma/ luto traigo por mi honor»:

el papel de Tamar en Los cabellos de Absalón

Javier J. González Martínez

Inés de Castro y la teoría del chivo expiatorio

\section{Dramaturgas}

María Luisa Lobato

Tres firmezas en una: amor, amistad y poder en

La firmeza en el ausencia de Leonor de la Cueva

Francisco Sánchez Ibáñez

Una hermana vengativa en la Corte de Lisboa:

El muerto disimulado de Ángela de Azevedo 


\section{Actrices}

Piedad Bolaños Donoso

Actrices en el siglo XVII. Notas sobre doña Manuela Enríquez, esposa de Juan Bautista Valenciano

\section{Crónicas de los coloquios}

Óscar García Fernández

Las directoras ante el teatro clásico español:

Helena Pimenta y Eva del Palacio

Alberto Gutiérrez Gil

Las actrices ante el teatro clásico español. Coloquio con

Pepa Pedroche y Paula Iwasaki

Óscar García Fernández

Crónica del coloquio sobre la representación de En otro reino extraño, por la Joven Compañía Nacional de Teatro Clásico

\section{Libros en escena}

Daniel Migueláñez

Cenizas de Fénix. Sobre vida y obra de Lope de Vega y

sor Marcela de San Félix

Almudena García González

Sor Juana Inés de la Cruz y el teatro novohispano.

XLII Jornadas de teatro clásico

\section{Romance de ciego}

Fernando Aguado

«Ojos que no ven...» (Romance de ciego)

Espectáculo de calle o kale-barroca 


\section{TRES FIRMEZAS EN UNA: AMOR, AMISTAD Y PODER EN LA FIRMEZA EN EL AUSENCIA DE LEONOR DE LA CUEVA}

\section{María Luisa Lobato}

UNIVERSIDAD DE BURGOS

Orcid: 0000-0002-4951-1309

http://doi.org/10.18239/cor_46.2021.06

Autora de una sola comedia, hasta donde sabemos, Leonor de la Cueva y Silva ${ }^{1}$ tuvo una vida que ocupó casi todo el siglo XVII (1611-1705). Mujer longeva, que ya escribía en 1628 un soneto epitafio a su tío, Francisco de la Cueva (ca. 1550-1628), todavía en 1689 compuso varios poemas a la muerte de la reina María Luisa de Orléans, esposa de Carlos II. Una vida, por lo que puede apreciarse, casi coincidente en el tiempo con la de Calderón de la Barca (1600-1681). Sin embargo, su obra se ha solido relacionar con la producción de Lope de $\mathrm{Vega}^{2}$.

1 Leonor de la Rúa Cueva y Silva, según documentos notariales, aunque adoptó el apellido de su tío Francisco de la Cueva, por el que suele conocérsela [Voros, 2009: 499].

2 Ha sido una constante de la crítica. Esta obra, en concreto, guarda algunas concomitancias con la comedia La firmeza en la desdicha, de Lope, en cuanto que el rey de Messina, Rogerio, nombra a su vasallo Leonardo general y lo envía a Cerdeña a sofocar una rebelión, para ańejarlo de su hermana, Teodora, y poder declararle su amor en ausencia de su hermano. Esta vez será el conde Octavio, enamorado de Teodora y padre de sus dos hijos, el encargado de actuar como intermediario para declarar a Teodora el amor del rey. En la obra de Lope, sin embargo, el rey no acosa a la 
Conocida más por su lírica que por su poesía dramática, su única comedia $\mathrm{La}$ firmeza en el ausencia ha suscitado en el último cuarto de siglo diversos acercamientos de interés, propiciados - sin duda- por la edición de la obra. Conservado el manuscrito autógrafo en la Biblioteca Nacional de Espańa [BNE], signatura MSS/17234, Serrano y Sanz realizó una primera transcripción impresa [1903: 302-328], que al menos permitía leer la comedia. Fueron luego Doménech y González Santamera [1994: 219-336] y Scott Soufas $^{3}$ [1997: 195-224] quienes nos acercaron de nuevo el texto de la obra, esta última aún con diversas cuestiones mejorables en la transcripción del mismo.
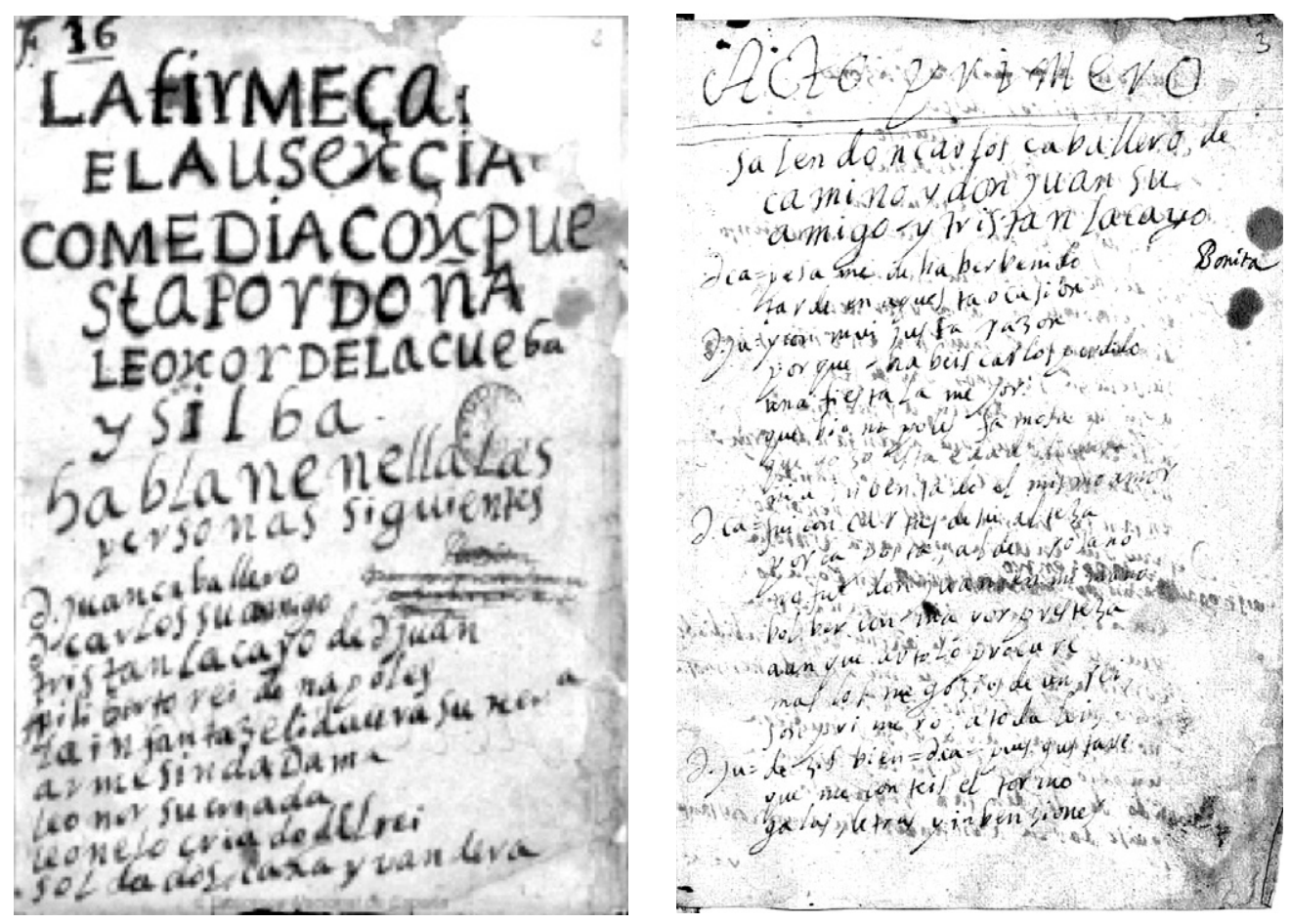

dama, aunque ella también sufre rapto e intentos de violación a manos de otro hombre, Ricardo. A pesar de todo ello, la obra termina también de forma positiva para los amantes Teodora y Octavio.

3 Por quien se cita el texto en este trabajo, corrigiendo ortografía y puntuación. 


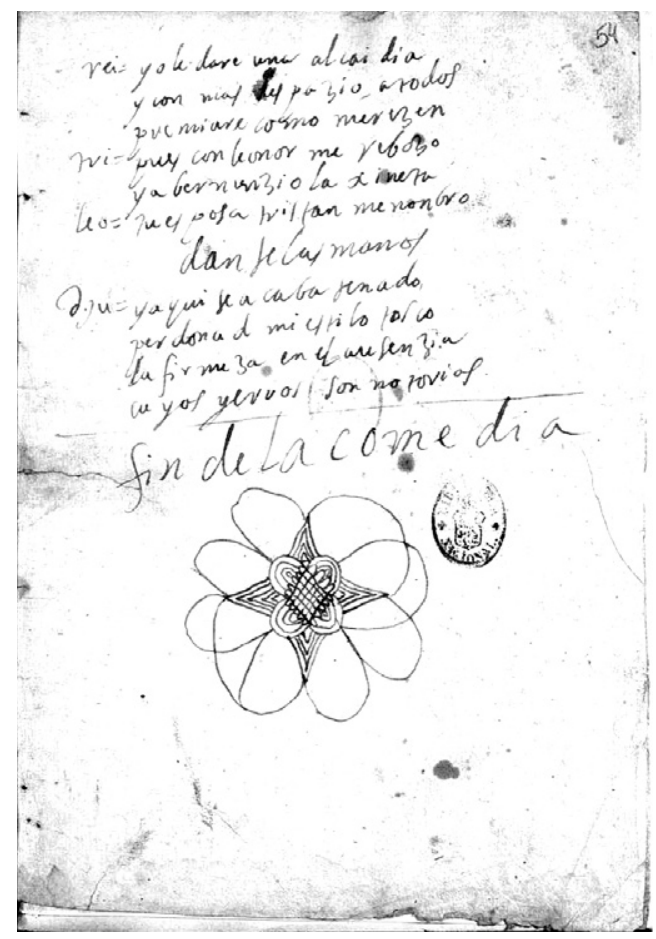

CBiblioteca Nacional de España

BNE MSS/17234, autógrafo, inicio y fin de la comedia

Aun teniendo en cuenta que su vida se desarrolló en Medina del Campo (Valladolid), ciudad que no estaba ya en su mejor momento, sus relaciones familiares hicieron posible que esta escritora participase de redes sociales y poéticas vinculadas a la corte. En efecto, tanto su tío, Francisco de la Cueva, como su hermano, Antonio de la Cueva, se movían en círculos cortesanos. 


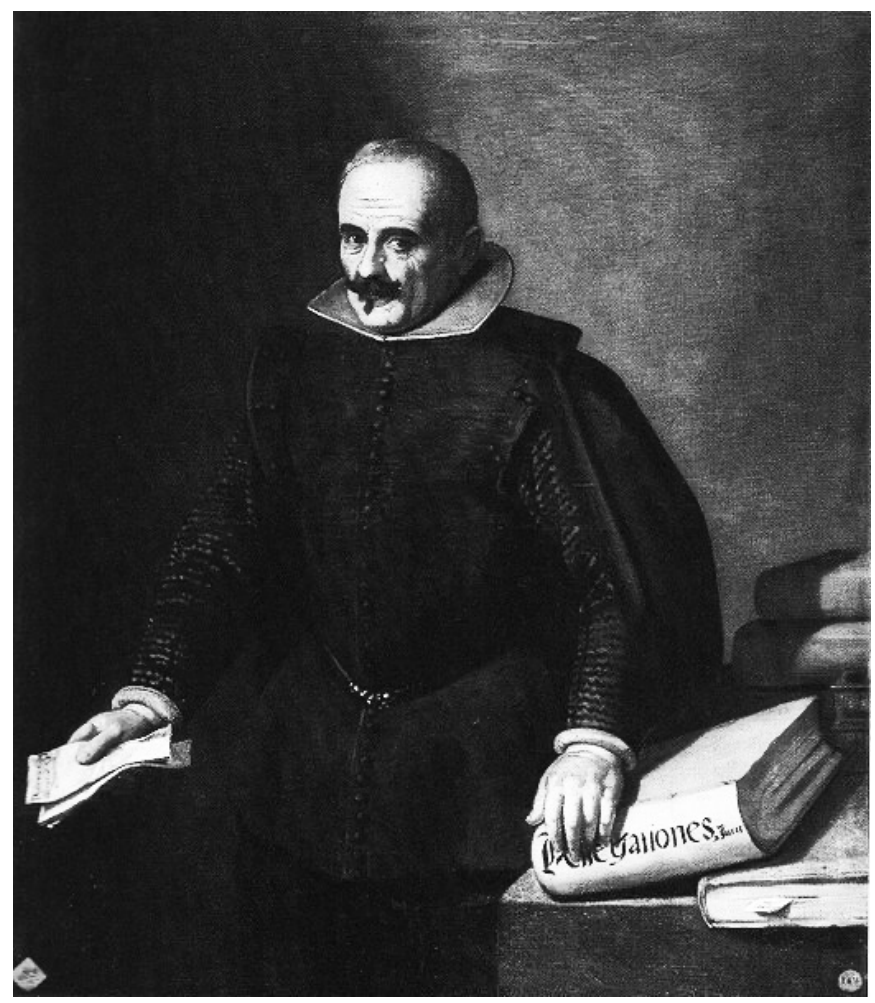

Juan Van Der Hamen (1596-1631). Francisco de la Cueva. Retrato del dramaturgo, filólogo y jurisconsulto español Francisco de la Cueva (ca. 15501628). ca. 1625. Real Academia de Bellas Artes de San Fernando

Este último, al servicio del infante don Fernando de Austria, fue capitán y comisario de la Caballería de Flandes, nombramiento para el que la escritora compuso un poema en octavas, pero fue su tío en su condición de hombre culto, jurista y abogado de las Cofradías de Representantes y Autores de Comedias, el que pudo con su biblioteca proporcionar un primer material de lectura a su sobrina Leonor, que quizá se conservó en la casa familiar tras su muerte en 1628. No es baladí que Lope de Vega le citase en once ocasiones entre los años 1620-1632, dedicándole un soneto en su fallecimiento ${ }^{4}$. No extraña, por tanto, que en el estrado de la dama Leonor, hubiese

4 El que comienza: «Paulo, jurisconsulto soberano» (Laurel de Apolo, silva III, vv. 383-396 [Vega, 2007]). Para la relación entre Francisco de la Cueva y Lope, puede verse Sánchez Jiménez [2015]. 
retratos de estos dos hombres y otros de su esposo, Beltrán Blásquez de Frías, lo que aleja definitivamente la idea de que la escritora era una mujer soltera. Si los libros que aparecen en su testamento no son muchos: seis o siete, detalla, entre los que estaba el Libro de para todos de Juan Pérez de Montalbán y dos volúmenes de su Silva de Apolo, que de momento no ha podido encontrarse. El Libro de para todos contiene, entre otras obras, la comedia La más constante mujer, que se relaciona estrechamente con La firmeza de Leonor de la Cueva [Voros 2009: 502-505]. Pero, sin duda, las posibles lecturas se prolongaban en los libros de su tío, al que debió la admiración suficiente como para querer firmar con su apellido: 'de la Cueva', cuando el de su padre era Rúa y el de su madre Silva. Por tanto, su nombre legal era Leonor de la Rúa y Silva, como figura en los documentos notariales.

\section{Mujer culta y escritora en el Parnaso de su tiempo}

Mujer, por tanto, lectora y próxima a la cultura, reivindicó su figura en algunas de las ocasiones más notables de su siglo, relacionadas todas ellas con el ámbito cortesano y, en concreto, con mujeres vinculadas al poder político. Tres son los momentos que prueban que su nombre contaba en la sociedad literaria y tenía también una adscripción pública: 1629 en que escribe el soneto "A la primera salida a Atocha de la Reina doña Isabel de Borbón después del nacimiento del Príncipe» [Baltasar Carlos]; 1645 en que dedica un poema "A la muerte de Isabel de Borbón», incluido en la colectánea Pompa funeral a doña Isabel de Borbón, celebrado en el convento de San Jerónimo de la Villa de Madrid (Madrid, 1645), que estuvo colgado -como era costumbre- en el crucero junto al de los otros escritores, y 1689 en que su texto poético "A la muerte acelerada de la Reina Nuestra Señora Doña María Luisa de Borbón»" se imprimió incorporado al libro Cisnes del Manzanares, en el que participaron autores cercanos a los círculos de poder de la monarquía.

5 «La flor de Francia,/ lis que a nuestra España» apareció en cuatro impresos distintos, sin año, entre otros en Lomas Cantoral, Cantos fúnebres de los cisnes del Manzanares a la temprana muerte de su mayor reyna doña María Luisa de Borbón..., s.l., s.a., 98 hs. fol. 98v. Este y los dos anteriores, pueden leerse en Serrano y Sanz [1903: 328-329]. 

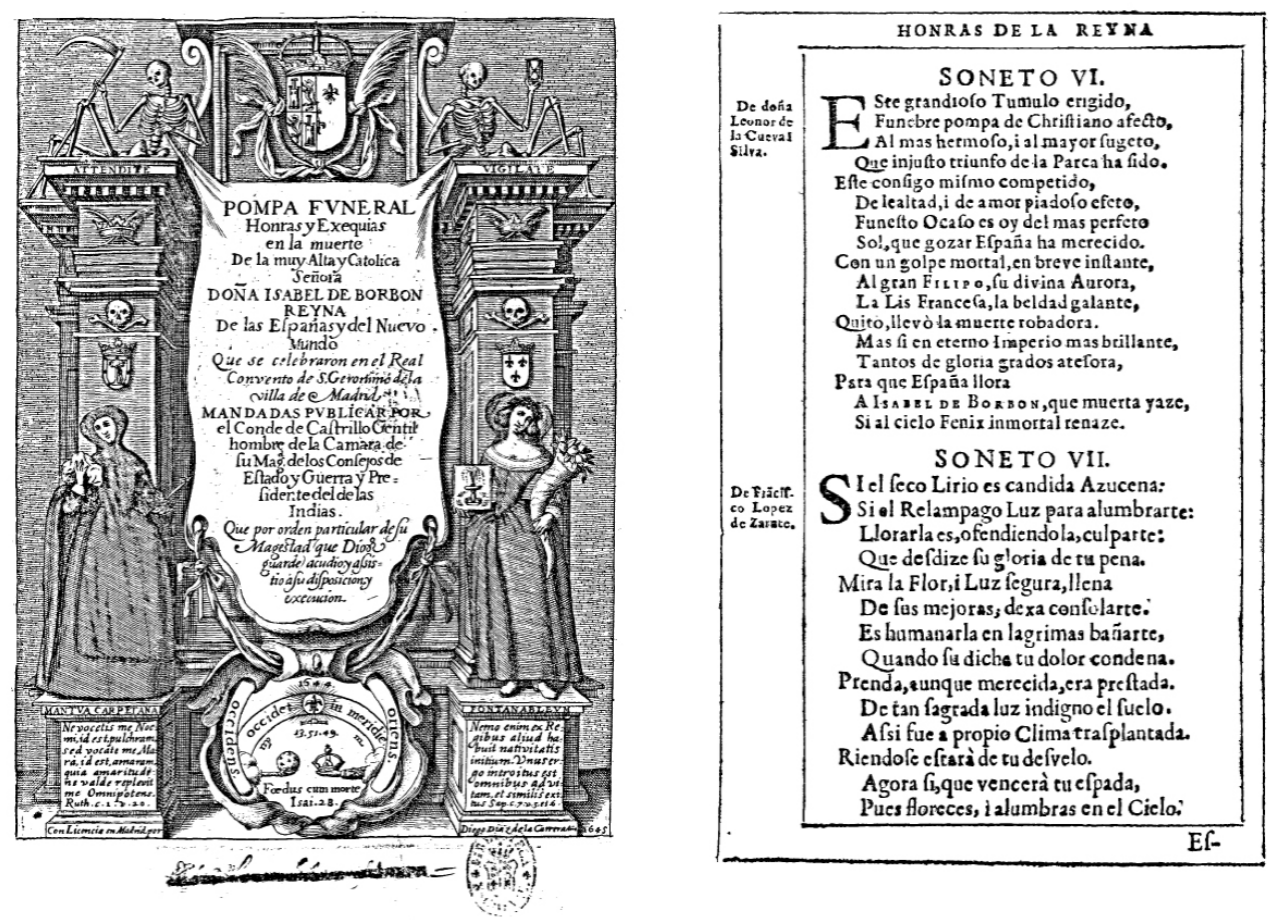

"A la muerte de Isabel de Borbón», incluido en la colectánea Pompa funeral a doña Isabel de Borbón, celebrado en el convento de San Jerónimo de la Villa de Madrid (Madrid, 1645). BNE R/3035

Estas publicaciones y otras de las que aquí no es posible hablar, prueban la presencia de Leonor de la Cueva en ámbitos más amplios que los de Medina del Campo, cercanos a la corte, a través de los cuales alcanzó una promoción social y literaria nada fácil para una mujer de su tiempo. Prueba de ello es el hábito de una de las tres órdenes militares que le dio el rey Felipe IV para quien se casase con ella, que su marido no llegó a heredar y ella dejó en su testamento para quien contrajera matrimonio con su sobrina nieta y heredera universal dońa Catalina Antolina de la Rúa Cueva y Silva [caja 6788, fol. 12411, cit. por Voros, 2009: 505].

Podríamos hablar también de lugares en los que no estuvo y, ya que se ha citado el Para todos (1632) de Juan Pérez de Montalbán (1602-1638), que tenía en su biblioteca particular a su muerte, es posible echar de menos su presencia en las Lágrimas 
panegíricas que se dedicaron a este dramaturgo en 1639 -por cierto, aún sin edición moderna- donde colaboraron más de una decena de escritoras de su tiempo sin que se encuentre ella entre los nombres impresos.

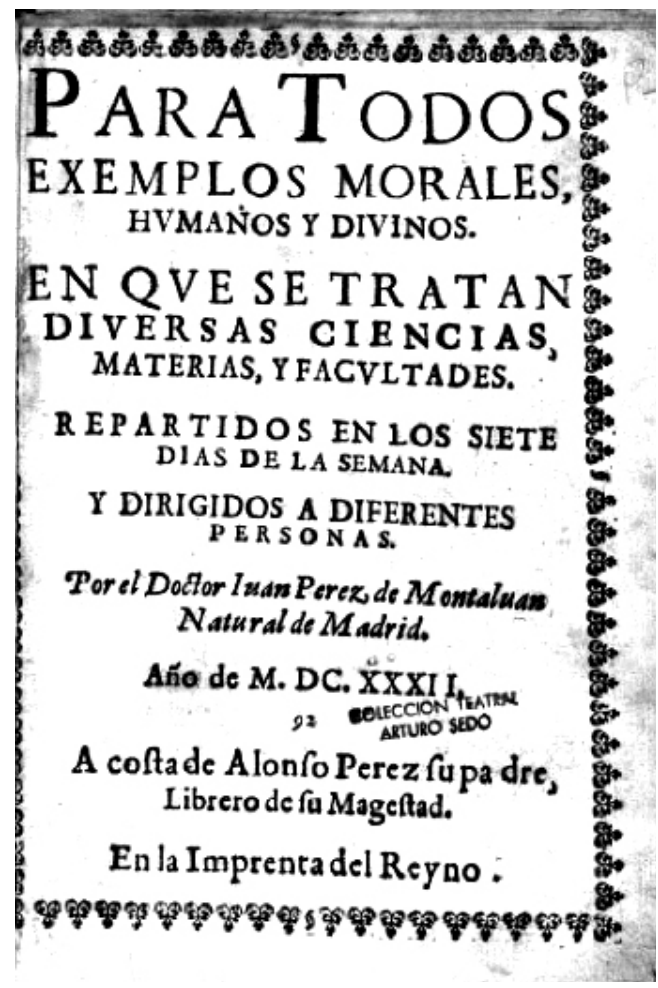

Como se ha podido ver, los tres sonetos citados marcan periodos vitales de su vida literaria: el inicio de la misma (1629), la madurez (1645) y el final de su existencia (1689), en todo caso un largo periplo dedicado a la poesía y al teatro. Sin que sea posible atender hoy a su obra lírica, que se conserva en la BNE, MSS/4127: 188 y ss., sí quisiera fijarme en dos poemas que guardan relación con su única obra dramática. Se trata, en primer lugar, del soneto que tituló «Todo lo pierde quien lo quiere todo» y dice así:

Muestra Galicio que a Leonarda adora, y con segura y cierta confianza promete que en su fe no habrá mudanza, que el ser mudable su firmeza ignora. 
Mas de su amor a la segunda aurora muda su pensamiento y su esperanza, y sin tener del bien desconfianza publica que Elia sola le enamora.

Con gran fineza, aunque si bien fingida, a Leonarda da el alma por despojos, y luego con un falso y nuevo modo dice que es Elia el dueño de su vida. Pues oiga un desengaño a sus antojos: todo lo pierde quien lo quiere todo ${ }^{6}$.

Tenemos en él una primera crítica a la volubilidad del amor masculino sin que sea posible saber cuál es el género del que habla, aunque parecería tratarse de una mujer.

El segundo soneto también se ocupa de la relación amorosa, esta vez en primera persona poética, y expresa la decepción al enterarse de que el amor del caballero es fingido. Retoma el tópico de la 'mujer ligera' -engañada por el amor aparente y los regalos-, para pasar en el terceto siguiente a manifestar su cambio de actitud: una vez conocido el amor mentiroso del caballero, ella toma de nuevo las riendas de su vida y termina con su firmeza en el amor e, incluso, con el recuerdo mismo de este.

Puse los ojos, jay! que no debiera en quien ya de las flechas de Cupido mostraba el tierno corazón herido, para que yo sin esperanza muera.

Huir fácil me fue de la primera ocasión que a tal daño me ha traído, con resistir mirar tan atrevido.

Mas fui mujer $y$, al fin, mujer ligera.

Grillos amor me puso a los sentidos

y la causa crüel de tantos daños con su regalo aumentó mis glorias.

Pero sabiendo, ¡ay, Dios! que eran fingidos, he sepultado en caros desengaños mi firmeza, mi amor y sus memorias.

6 «Quien todo lo quiere todo lo pierde», dice el refrán castellano. Tomo este texto y el que sigue de Serrano y Sanz [1903: 331 y 332, respectivamente]. 
En ambos casos, la interlocutora anónima expresa su superioridad respecto a la situación que se presenta: con una máxima admonitoria en el primer soneto: «todo lo pierde quien lo quiere todo» (v. 14), con dos versos que expresan un cambio de actitud voluntario y radical en el segundo: «he sepultado en caros desengaños/ mi firmeza, mi amor y sus memorias» (vv. 13-14). En todo caso, quien habla, en el segundo caso de forma explícita como mujer, es un personaje libre, capaz de juzgar sobre actuaciones ajenas y de tomar decisiones resolutivas sobre las mismas.

\section{ENTRE HISTORIA Y FICCIÓN, LA COMEDIA PALATINA LA FIRMEZA EN EL AUSENCIA}

Y yendo ya a la comedia que da título a esta presentación, La firmeza en el ausencia, se calcula escrita a mitad del siglo XVII y, por tanto, en un punto de madurez artística de su autora. La obra reúne elementos propios de la escritura de una mujer culta, como se tratará de demostrar y no solo por su estilo literario sino también por la historia sobre la que se teje.

Instalado el espacio dramático de esta comedia cortesana en Nápoles, con personajes nobiliarios — rey, nobles, caballeros y damas- y en un tiempo alejado del contemporáneo a la escritora, unos ciento cincuenta ańos aproximadamente, toma sus mimbres en un juego entrelazado de historia y ficción, pues si ficticios son sus personajes, la autora nos permite atisbar hechos sucedidos de gran importancia para la relación entre Espańa, Italia y Francia durante la segunda guerra de Nápoles y el inicio de un periodo glorioso de la corona espańola sobre Nápoles, como diremos a continuación.

En efecto, en diciembre de 1503 las tropas de Gonzalo Fernández de Córdoba (1520-1521/1578), el Gran Capitán, vencieron a las francesas en la batalla entre los ríos Garellano y Gaeta, lo que atrajo a Nápoles a la corona espańola. La obra, por tanto, recordaría a su público - preferentemente cortesano- uno de los momentos álgidos de la historia militar de España. Si bien no nos han llegado noticias de la representación de esta comedia, es muy probable que la hubiera y, desde luego, esa debió de ser la voluntad de la escritora. 


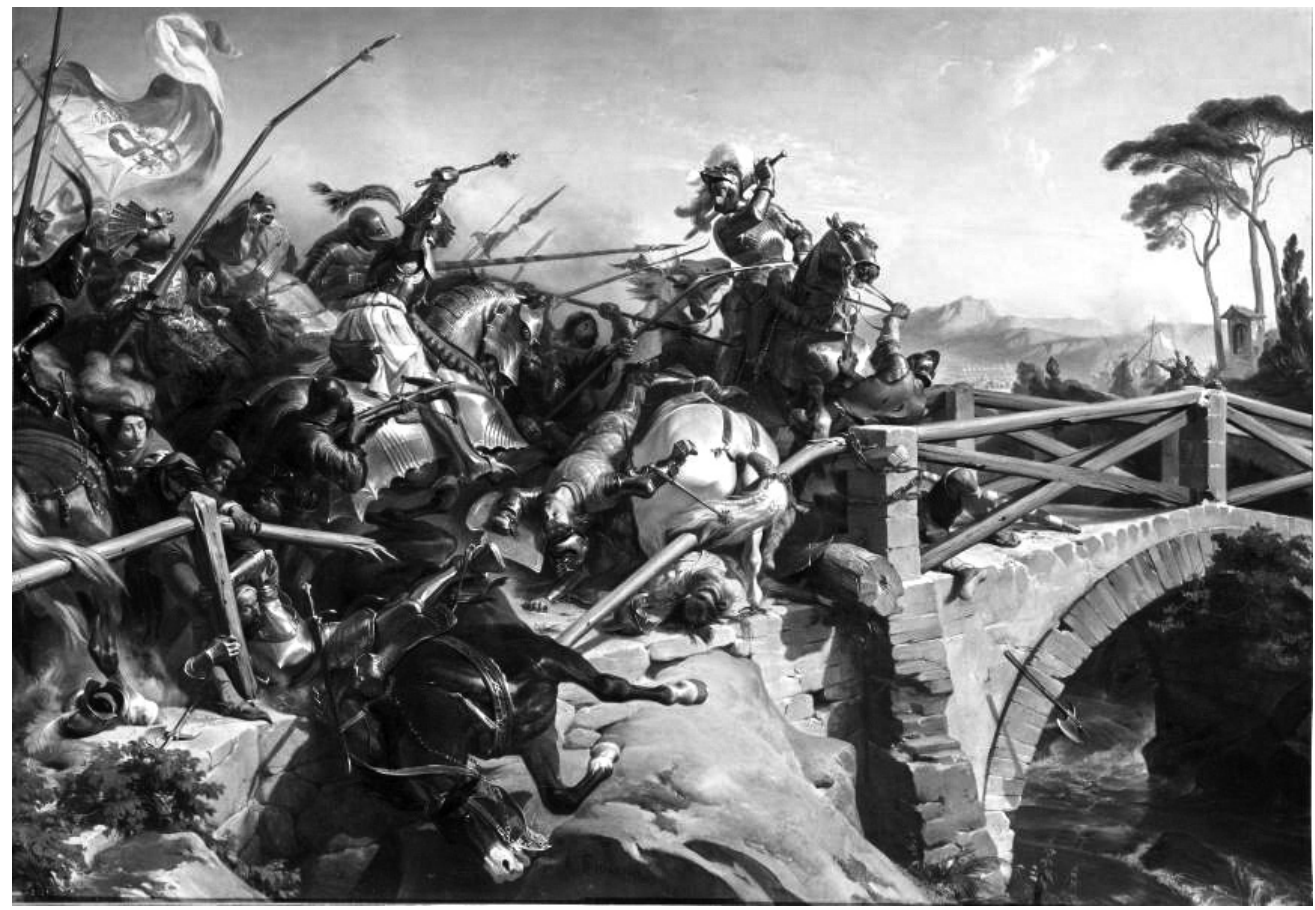

Henri Félix Philippoteaux (1815-1884), Batalla del río Garellano. Palacio de Versalles

Se equivoca, por tanto, Stacey L. Parker Aronson cuando indica que «Cueva situates the drama during 1640s-1660s, aunque la afirmación que sigue: "the time of the French invasión of Naples» y "nearly a century before it was actually believed to have been written, some time during the early or middle XVII century» [2007: 143] nos hace pensar que quizá Parker Aronson donde escribió 1640-1660 para el tiempo dramático, se estaba refiriendo al momento en que Leonor de la Cueva redactó la comedia, ya que el tiempo dramático, fue, como se ha dicho y se explicitará ahora, un siglo y medio antes, 1503, pues los datos históricos que subyacen en el texto no dejan lugar a dudas.

La acción amorosa que protagoniza la pieza se entreteje con la guerrera. Ya en la primera jornada, el protagonista don Juan presagia la llegada de malas nuevas del rey en la carta que le trae Leonelo: "y me avisa mi temor/ que esto es venganza de amor» (vv. 158-159). La lectura de la carta permite acercarnos al episodio histórico del Gran Capitán, enviado por el rey Fernando el Católico a Nápoles para luchar con- 
tra el enemigo francés, aunque la acción bélica en ningún momento se corresponde con los nombres históricos. Aquí es el príncipe de Rosano el que avisa al rey Filiberto [Fernando el Católico], de que «el rey de Francia [Luis XII], con mano armada, ha entrado por las tierras de Nápoles» y que «a vos os toca la defensa de mis reinos» (v. 161). A don Juan, nuevo Gran Capitán, solo le resta aceptar.

Buena parte de los hechos que soportan la acción dramática en la segunda y tercera jornadas se refieren a este episodio, en el que la autora pudo dejarse guiar por alguna fuente escrita sobre las guerras de Italia, pues no son pocas las precisiones que se dan de los principales espacios en que se desenvolvió la contienda ${ }^{7}$, recordada en numerosos escritos entre los que se encuentra el libro de Cantalicio en 1607. Tampoco extrańa que conociera lo principal de la acción a través de transmisión oral, pues formaba parte de un momento álgido de la historia de Espańa. Pero algunos de los detalles que se dan en la obra permiten establecer la hipótesis de que seguía fuentes escritas, por ejemplo, los topónimos que salpican la tercera jornada: Venosa (v. 2662), Basilicata (v. 2304) y Barleta (v. 2306), entre otros, todos ellos vinculados a la zona de Puglia y relacionados con la guerra citada. También son históricos algunos nombres de personajes, como el capitán Pocodinare (v. 2263), que tiene el sustrato histórico del capitán Luis Dares Pocodinare, el cual guió las tropas frente a los adversarios: Bartolomé de Alviano y Próspero Colona. Tanto los topónimos como los antropónimos se mencionan en las obras más detalladas sobre esta batalla, como es el libro de Cantalicio ya citado. Por todo ello, es posible establecer la hipótesis de que la autora seguía fuentes escritas, aunque tratándolas con gran libertad.

7 Son varios los libros que circulaban por Italia y España en los siglos XVI y XVII en que se detallaba lo ocurrido. Entre los principales, y muy cercano en fechas a las de Leonor de la Cueva, estaba la Neapolisea. Poema heroico y panegírico al Gran Capitán Gonzalo Fernández de Córdoba, de Francisco de Trillo y Figueroa, impreso en Granada, por Baltasar de Bolibar y Francisco Sánchez, 1651, aunque solo en el Libro Séptimo se refiere a este episodio. Mucho más detalle había en el Libro Cuarto de Le historie di Monsiggio Battista Cantalicio [...] delle guerre fatte in Italia da Gonsalvo Ferrando di Ailar di Cordoba, detto il gran Capitano, publicado en Nápoles, por Gio Giacomo Carlino en 1607. Agradezco estas noticias a Encarnación Sánchez, profesora de l'Università di Napoli L' Orientale. 


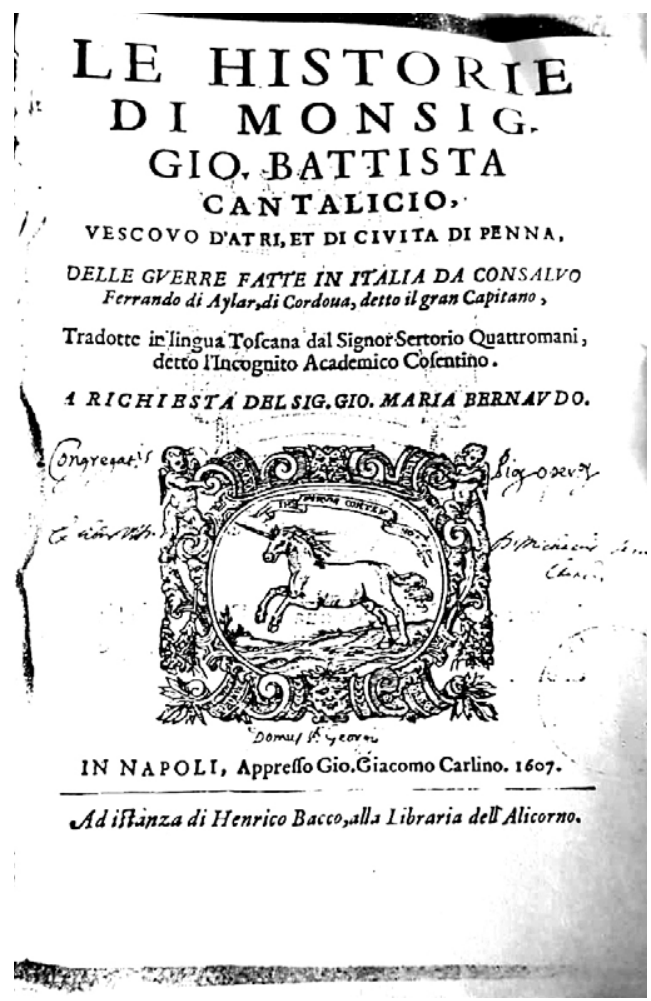

En la segunda jornada, las referencias al triunfo en el río Garellano sobre las tropas francesas ocupan un lugar central (vv. 1213-1260), marcado por la presencia de redondillas que asaltan el texto entre las tiradas de romance anterior y posterior. Protagonizado el pasaje por don Juan y tres soldados, el lenguaje bélico lo invade todo. La satisfacción por haber vencido a los franceses (vv. 1213-1214) va seguida por la alabanza del soldado $1^{\circ}$ a su capitán, don Juan, diciendo de él que es «el mismo Marte» (v. 1218) e «invicto vencedor» (v. 1220). La redondilla del soldado $2^{\circ}$ en que sobrepuja a don Juan por encima de algunos de los grandes guerreros: «No te igualan ipesia tal!/ César, Pompeyo romano,/ Scipión, el bravo africano,/ ni de Cártago, Anibal» (vv. 1217-1220) merece que su capitán prometa escribir a Su Alteza para que premie la lealtad de estos hombres (vv. 1229-1232). El texto dramático da cuenta de los nuevos planes de don Juan, que dice estar al tanto de que llegan más tropas francesas por mar y que el mismo rey de Francia las lidera, por lo que promueve una 
maniobra militar (vv. 1237-1247). Finaliza el pasaje con el soldado $3 .^{\circ}$ que le desea: «Nápoles su rey te vea» (v. 1257).

La tercera jornada presenta el avance de don Juan victorioso hacia Nápoles, seguido de sus soldados y, por supuesto, del criado Tristán. En la segunda mitad de esa jornada, entra don Juan y en un largo monólogo de doscientos trece versos narra al rey, en presencia de Armesinda y de Leonor, lo ocurrido en el camino a la batalla, el encuentro militar mismo, los ardides para ganar a las tropas francesas a pesar de la desigualdad del número de guerreros y, en especial, se detiene en la descripción de la batalla junto al río Garellano, la victoria contra los franceses y la llegada del embajador del rey de Francia para pedir la paz.

Sus palabras traen, además de la noticia del triunfo bélico, la petición del rey francés de "que la infanta, mi señora [dice don Juan],/ sea de las lises de oro» (vv. 2358-2359). A cambio «él [el monarca francés] te dará a su hermana,/ madama Blanca, en retorno,/ cuya belleza verás/ en este retrato hermoso» (vv. 2360-2363). Se encamina así el final de la comedia, en el que el rey aceptará las bodas entre don Juan y Armesinda, la suya con dońa Blanca y, como suele ocurrir en la comedia española, también los criados Tristán y Leonor anuncian su enlace.

Sin duda, Leonor de la Cueva conocía este pasaje de la guerra entre España y Francia por la conquista de Nápoles y tras los personajes de su obra estaban de alguna manera presentes los protagonistas de aquel momento: el rey español, Filiberto, que solo como speculum principis a la inversa — veremos el porqué más tarde- puede recordar al monarca Fernando el Católico en el periodo en que se enmarca la obra; el protagonista, don Juan, capitán valiente, por Gonzalo Fernández de Córdoba, Gran Capitán, vencedor de la famosa batalla del río Garellano -también nombrado en la comedia- y no son pocas las referencias al rey francés, el enemigo a batir, al que se hace referencia en el v. 1383, aunque sin darle su verdadero nombre, Luis XII.

El sustrato de uno de los episodios históricos más importantes para la España de principios del siglo XVI no es, sin embargo, algo intercalado en la comedia y que pueda desgajarse de ella. Este otro procedimiento se ve, por ejemplo, en comedias de ese periodo como la titulada De fuera vendrá de Agustín Moreto, en la que se recoge un episodio de la guerra contra los franceses en Girona durante la década de 1640. Como su editora ya demostró [Gavela García, 2010: 7], se trataba en aquel caso de realizar a través de la comedia un homenaje a Francisco Fernández de la Cueva ( $c$ a. 1619-1676), duque de Alburquerque, recién llegado a México en 1653 como virrey y amigo personal de Moreto, además de mecenas, por lo que recordar esas batallas en 
las que habían intervenido familiares y conocidos de Fernández de la Cueva era un modo de honrarle .

Teniendo en cuenta que no pocas comedias áureas tuvieron el fin de alabar a una genealogía, ¿sería posible pensar que en el sustrato de La firmeza en el ausencia latía un homenaje a la familia del Gran Capitán y por ende, también a los antepasados comunes entre este y la dramaturga, vinculados al ducado de Alburquerque? Siendo ella sobrina de Francisco de la Cueva, escritor, pero también jurista y político arraigado en la corte, no debería extrańar, si bien no es posible probarlo en este momento. En todo caso, la manera en que se dispone de la historia es muy diferente en las dos comedias nombradas. Si en De fuera vendrá los hechos siguen fielmente la descripción de una crónica', en La fortuna en el ausencia son la trama sobre la que su escritora establece una acción cortesana, más vinculada con los afectos que con hechos bélicos externos.

La obra debió representarse en su tiempo, quizá en un contexto palatino, pero no se han encontrado de momento referencias. La tradujo al inglés Sharon D. Voros y se puso en escena con el título Tried and True el 23 de noviembre de 2013 en el Teatro Stage II de Oklahoma City University, dirigida por David Pasto.

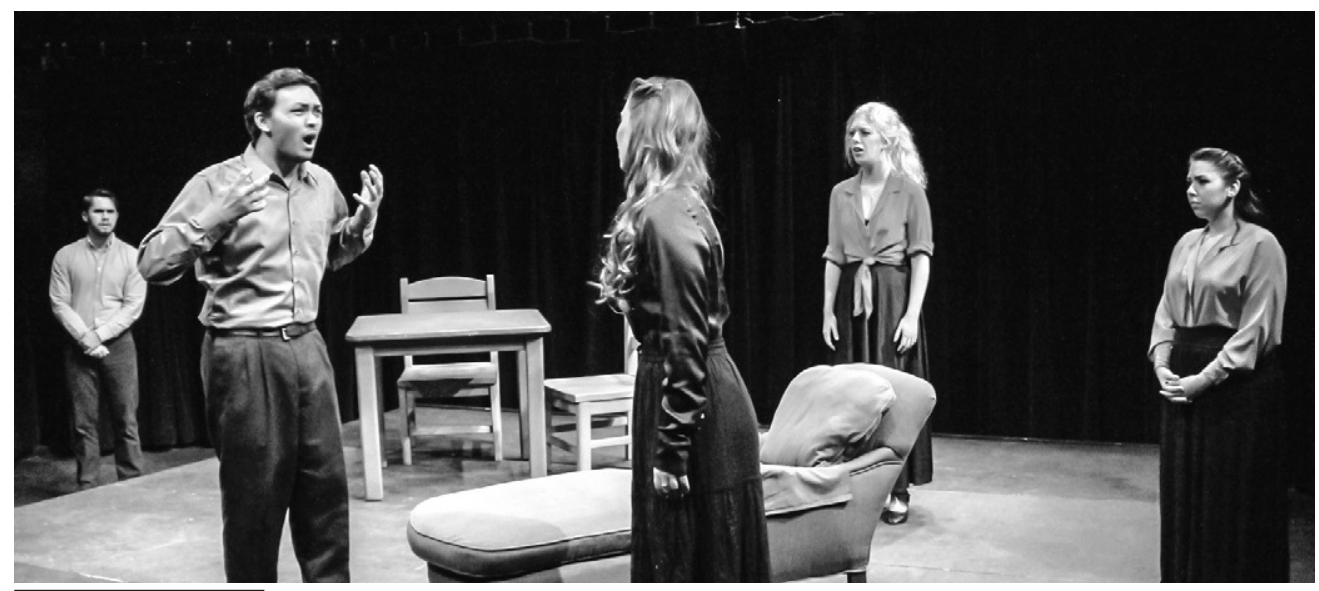

8 Por cierto, que Fernández de la Cueva era duque de Alburquerque y un miembro de esa familia nobiliaria había reemplazado al Gran Capitán en el gobierno de Italia un siglo antes, en 1563. Tampoco conviene olvidar que Francisco de la Cueva, tío de Leonor, descendía también de la estirpe de los Alburquerque, todo un cúmulo de casualidades en las que ahora no es posible entrar.

9 Verdadera relación muy copiosa del socorro que el serenisimo señor Don Juan de Austria Príncipe de la Mar, dio a la Ciudad de Girona, el miércoles 24 de septiembre deste año de 1653, Sevilla, por Juan Gómez de Blas, año de 165 ejemplar de la Biblioteca Nacional de Espańa, VE/1384/27. 


\section{LA GUERRA DE ARMAS COMO ESPACIO SIMBÓLICO}

Sin embargo, no es el objetivo de esta comedia literaturizar una batalla, ni siquiera la inolvidable del río Garellano. En este sentido contradice lo que Sullivan definió como la doble estructura de la comedia áurea:

The main actions of Golden Age Spanish dramas concern law, expressed as issues of power politics, ant the secondary actions concern desire, expressed as issues of love and passion. [Sullivan, cit. por Scott Soufas, 2000: 146]

La guerra de armas que hasta aquí se ha recordado se convierte en espacio simbólico de las duras batallas que se librarán en esta comedia en torno a una de las emociones más presentes en la cosmovisión áurea, como es la 'firmeza', por la que se entiende en su tiempo: "Estabilidad, constancia, seguridad y fortaleza» (Autoridades, 1732). En concreto, en la obra que nos ocupa, la firmeza se refiere de forma prioritaria a la 'constancia en el sentimiento amoroso' pero no solo en esa emoción, ya que también abarcará la firmeza en la amistad y la estabilidad en el vasallaje. Un eje axial, por tanto, de tres manifestaciones de una misma emoción, si así la podemos llamar avant la lettre. Y, sin que queramos forzar el texto con interpretaciones establecidas en épocas posteriores, no podemos dejar de situar esta obra en el contexto del análisis de los sentimientos humanos y, por tanto, en la línea de los estudios sobre las emociones tan vigentes desde mitad del siglo XX. Mucho camino se ha recorrido desde los pasos iniciales de Lucien Febvre en su artículo «La sensibilité et l'histoire» publicado en $A n$ nales, en el que proponía que las emociones se situaran en el centro de la investigación histórica [Febvre, 1941]. La nuestra, en historia literaria, no puede dejar de recoger aquel envite que muchos otros han tenido en cuenta desde entonces, aunque aplicada a un contexto de ficción teatral que tiene sus propias peculiaridades. Porque vamos a hablar de 'firmeza', sí, pero a una distancia de casi cuatrocientos años, ¿̇tiene el mismo sentido el término entonces que hoy?

Volvamos al lenguaje de la guerra. Batalla es la que libra don Juan frente al rey Filiberto por su amada Armelinda, como demuestra el lenguaje que emplea cuando los soldados abandonan la escena y despliega su largo discurso de cuarenta y cuatro versos dirigido a una «ausente celestial» (v. 1263). En él va asociando términos de la vida militar con los de su lucha por conseguir a la dama: en esta guerra, sus recelos son vigilantes soldados que le tienen cercado (vv. 1270-1274), las penas y pensamientos son el bagaje, y sus suspiros y tormentos son balas de arcabuces que disparan fogosos 
tiros al viento (vv. 1275-1279). Pero, aun en medio de la difícil situación, don Juan confía en la victoria de la firmeza honrosa, que es «valiente capitán» de esa batalla (vv. 1295-1299), aunque sea consciente de que un poder superior le avasalla y gobierna. La referencia al rey en un pasaje de gran barroquismo presenta a su verdadero enemigo: «Entre oscuros negros velos/ contra mí el poder, sin ley,/ viene escalando los cielos,/ ¿pues de qué sirve, si es rey,/ referirte mis desvelos?» (vv. 1300-1304).

$Y$ es que, en efecto, tenemos en esta comedia un rey lujurioso, que se diría descendiente del bíblico David, el cual no duda en enviar a uno de sus mejores hombres, el capitán don Juan, al frente de batalla, como un nuevo Urías, para alejarlo de Betsabél Armesinda ${ }^{10}$. El propósito es claro: el monarca, enamorado de la dama del guerrero, intentará seducirla en su ausencia ${ }^{11}$. Tiene para lograrlo un intermediario de amores, el caballero don Carlos, pero de lo que no es tan consciente es de que, aun contando con el vasallaje que le debe, don Carlos es amigo personal de don Juan y le guarda fidelidad. Tenemos, pues, tres 'firmezas' en lid: la de los enamorados: don Juan respecto a Armesinda, que es correspondida por ella; la de la amistad entre don Juan y don Carlos, y la del rey en su lujuria, que trata de vencer la voluntad de la dama. Pero el nudo gordiano de las tres firmezas es, sin duda, la actitud de Armesinda que tiene la clave para mantenerse fiel a su amado don Juan, conseguir que el pacto de guardarla que don Carlos hace con don Juan se pueda llevar a efecto, a pesar de las dificultades, y, lo más difícil, lograr mantener la sensualidad del rey a raya hasta el regreso de su amado $^{12}$.

La firmeza, que podemos entender también como 'fidelidad mantenida a un compromiso", se inclina en el título de la comedia al ámbito de "la ausencia», lo que dirige nuestra mirada a la protagonista. Va a ser la ausencia del amado, enviado a la guerra por el rey para alejarlo de Armesinda, la prueba principal por la que ha de transitar su protagonista y en torno a la cual se articulan las acciones. $\mathrm{Y}$ estas se conciben en el paratexto de la batalla a la que se ha hecho ya referencia en el apartado anterior. Lo que antes era guerra de armas es ahora guerra de voluntades.

La $1^{a}$ jornada de la comedia presenta ya lo esencial de la acción y servirá de motor a lo que sigue. Lo expone por primera vez don Juan a su amigo don Carlos cuando le confiesa el amor que atrapa su alma como si fuera una mariposa «deslumbrada al

10 Puede verse la historia completa en el Segundo Libro de Samuel, 11.

11 No me parece que la riqueza del rey sea un motivo de seducción tan importante como apunta Scott Soufas [2000].

12 Sobre el rey que abusa de su poder y pierde así autoridad, puede verse el cap. 2 de Scott Soufas [1997]. 
candor/ de los ojos de Armesinda» (vv. 248-249), un imán atraído por el hierro (v. 257) o la rosa por el sol (v. 258). Don Juan confiesa saber el peligro que acecha a su amada: «el rey quiere a Armesinda/ y pretende su favor» (vv. 267-268), que es la razón de que le envíe a «la guerra del de Francia» como general (vv. 279-281). Pero el dolor de don Juan no es solo por la actitud del rey ni por su ausencia impuesta, sino, sobre todo, porque duda de la firmeza de su enamorada: «viendo que me voy/ Armesinda, y que la quiere/ un rey de tanto valor,/ se rendirá a sus halagos (vv. 286-289) y la razón que da es un imperativo con visos de categórico, que no deja en muy buen lugar la figura femenina: «pues nunca menos se vio/ en una mujer ausente/ que apetecer lo mejor» (vv. 290-292) y que reiterará al final del pasaje: «no os espantéis de que tema,/ que es mujer y amante soy» (vv. 331-332). Tenemos, pues, los peligros de la ausencia desde el punto de vista del enamorado.

La dificultad del momento lleva a don Juan a buscar la firmeza en la amistad de su amigo Carlos, al que encomienda: «yo os dejo por otro yo/ para que, Argos vigilante,/ con más ojos que el pavón/ guardéis la prenda que adoro/ de este tirano rigor» (vv. 302-306). Carlos, en efecto, en uno de los momentos de la obra más barrocos y con mayor número de referencias culturales, acepta el envite:

\author{
Antes faltará a los cielos \\ de Admeto el rubio pastor, \\ al mundo azul las estrellas \\ y de Cintia el resplandor, \\ al prado su primavera \\ al árbol la fruta y flor, \\ al mar los peces y al día \\ bella esposa de Titón, \\ que yo falte en tu servicio, \\ y no es exageración, \\ pues diera por ti mi vida, \\ cuanto valgo y cuanto soy. (vv. 339-350)
}

Armesinda tiene noticia de que ausentan a su amado a través de su carta y también de la razón de su marcha: «iEl rey me ausente a don Juan!» (v. 434), y reaccionará con la primera declaración de su firmeza en el amor ante la actitud del rey: «Pero pierda la esperanza,/ porque antes verá acabado/ todo ese cielo estrellado/ que en $\mathrm{mi}$ amor haya mudanza» (vv. 437-440). La protagonista sabe que la respuesta que dé a la situación tendrá valor de ejemplar y asume esa responsabilidad: «he de amar hasta 
morir,/ por que se pueda decir/ que hay firme alguna mujer» (vv. 450-452). La misma actitud manifiesta versos más tarde al encontrarse con don Juan: "Del rey la fuerza amorosa/ no te dé, don Juan, disgusto,/ que en el resistir su gusto/ verás mi firmeza honrosa» (vv. 569-572). Y, por mantenerla, está dispuesta a morir: «La muerte, don Juan, me rinda,/ antes que falte a mi fe» (vv. 599-600).

Pero el momento cumbre en la declaración de la firmeza en el amor, serán los sonetos que intercambian estos dos personajes en el centro de la jornada, propios de una escritora como Leonor de la Cueva, autora de una importante producción lírica. Los sonetos son una declaración de fidelidad por parte de cada uno de los enamorados con una estructura paralela de juramento «Si yo ingrata, olvidare tus amores/ ni burlare, mudable, tu esperanza» (vv. 605-606) comienza Armesinda,/ «Pues si dejarte un punto de quererte/ ni olvidare jamás tu rostro hermoso» (vv. 619-620) inicia el suyo don Juan, para ir seguidos cada uno de ellos de once versos llenos de terribles consecuencias en caso de que se cumpliese el desamor, hasta finalizar el último de cada soneto con la promesa de fidelidad: «si yo, don Juan, dejare de adorarte» (v. 618) / «si dejare, Armesinda, de adorarte» (v. 632). En el marco de una comedia palatina, como estamos, seguidora en muchos de sus parámetros de la práctica teatral de Lope de Vega, no extraña que, tras el diálogo en que prueba la firmeza de su amor, y los sonetos encontrados de la dama y el galán, a los que se acaba de hacer referencia, a su salida de escena, se produzca el encuentro de la pareja de criados: Tristán y Leonor. En una acción paralela, también Tristán expone el temor a ser olvidado y su compañera afirma su correspondencia amorosa. De nuevo dos sonetos exponen su situación interior y continúan el esquema prefijado en los de sus amos. A un inicio de dos versos en que Leonor afirma: «Si yo olvidare, cielo, eternamente/ el amor y las gracias de Tristán» (vv. 653-654)/ se corresponde el inicio del gracioso: «Pues si yo te olvidare, mi Leonor,/ ni borrare del alma tu retrato» (vv. 667-668), para continuar con versos adecuados al estilo bajo de los criados y terminar con endecasílabos paralelos: «si yo dejare, mi Tristán, de amarte,/ porque eres el candil de aquestos ojos» (vv. 665-666) / «si yo, Leonor, dejare de quererte,/ porque eres las niñitas de estos ojos» (vv. 680681). No son, desde luego, habituales cuatro sonetos en una jornada de comedia. Su empleo manifiesta la pericia lírica de Leonor de la Cueva y también la conceptual en este juego de dos a dos perfectamente trazado, en el que se muestra también cercana a la perfecta arquitectura de escenas similares en el teatro de Calderón de la Barca. 

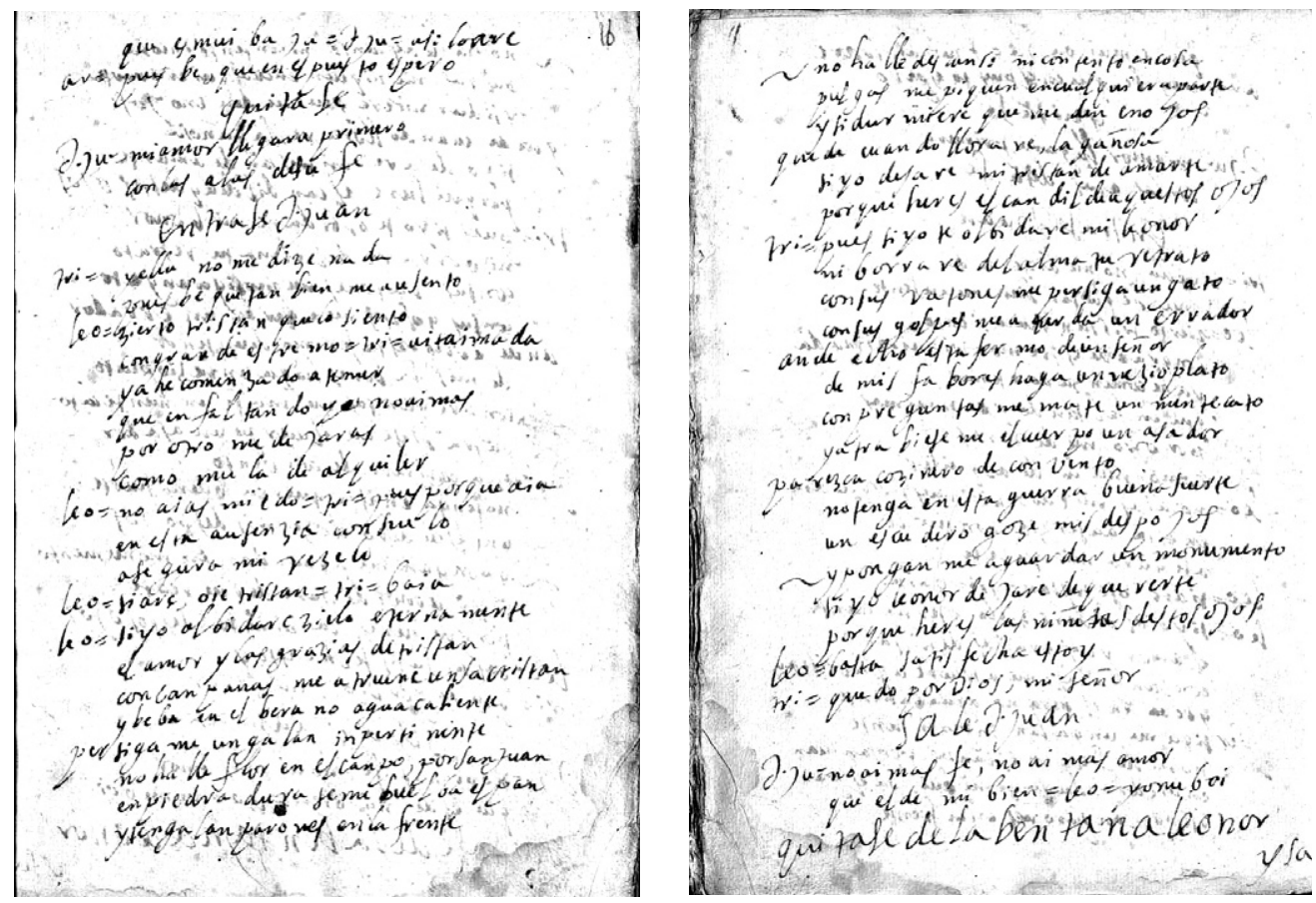

BNE MSS/17234, autógrafo, fols. 16-16v

Tras este juego poético, que ha dado movilidad conceptual a la acción, llega el planto que entona don Juan para terminar esta $1^{\text {a }}$ jornada, en presencia de Tristán. Su interlocutor es etéreo: amor y temor (v. 729), sus imprecaciones se dirigen al cielo airado (v. 753) y encarga a los elementos de la naturaleza: noche (v. 773), estrellas (v. 777) y sol (v. 781), que transmitan a su amada su pesar. Su duda entre marchar y quedarse nos recuerda a Teodoro en El perro del hortelano, aunque si allí era un juego dialéctico con la dama que le rechazaba, aquí manifiesta el vaivén sicológico de un sentimiento verdadero: "¿Es posible que me voy?/ No es posible, no lo creo,/ que el alma se queda acá,/ y solo se parte el cuerpo» (vv. 769-772). La jornada termina con Tristán haciéndole volver a la realidad del hambre y el sueño de las altas horas en que están.

También en esta $1^{\text {a }}$ jornada queda expuesta por primera vez la voluntad firme del rey: «Mátanme celos/ y anégame un mar de amar» (vv. 409-500) y su maldad al alejar a su contrincante en el amor: "Ofreciose esta ocasión/ en que de aquí le he 
ausentado,/ con que quedaré vengado/ sea o no sea razón» (vv. 505-508). Y da como razón que amor es rey y solo ha de guardar la ley del gusto (vv. 509-513). De nada sirve que su hermana, la infanta Celidaura, le amoneste que «quien tiene discreción,/ sujétese a la razón» (vv. 514-515).

Aunque no será objeto de este estudio, sí podría situarse al monarca y su violencia amorosa dentro del campo del 'Derecho y emociones', que tan buenos resultados está dando dentro del análisis de las emociones ${ }^{13}$. En concreto, en este caso interesaría la manera en que el comportamiento de quien tiene poder político puede sojuzgar las prácticas sociales e individuales. Para los historiadores de las emociones, la ley, en el sentido de la teoría jurídica, codificaciones y práctica, ofrece una perspectiva muy prometedora sobre cómo las emociones han sido conceptualizadas históricamente y de qué manera estos conceptos han dado lugar a relaciones interpersonales. Desde luego, pienso con Plamper que no existe una universalidad de las emociones y que el tiempo y el espacio mediatizan la manera en que se desarrollan y las percibimos [Plamper, 2014: 20]. El derecho penal es especialmente importante para este fin cuando se ocupa de temas como los crímenes pasionales y los crímenes de honor (incluidos insultos y ofensas) [Frevert, 2014: 52]. Ambos han sido percibidos y tratados como actos criminales y así se presentan también en esta comedia, aunque el desenlace de la obra logre 'distraer' al monarca del castigo que habría merecido de no cejar en su empeño de poseer físicamente a Armesinda. Resultaría interesante observar la relación entre estos dos personajes a la luz de las emociones que señala Frevert: las justas / injustas y aceptables / despreciables. Estos discursos no fueron solo teóricos, si bien todavía en el siglo XVII estaban lejos las consecuencias prácticas de la administración de justicia cuando se refería a la máxima autoridad del reino. El análisis de un hecho como este, el intento de violación de una subordinada, merecería un enfoque desde una perspectiva diacrónica y comparativa de legislatura y jurisprudencia, como bien apunta Frevert [2014: 52].

Las tres firmezas continúan en el desarrollo de la $2^{a}$ jornada. La insistencia del rey en violentar a Armesinda — no me atrevo a decir 'amar' —, expresada a través de una carta llevada por don Carlos, tiene como respuesta la indiferencia de ella: «Dila, señor, el papel,/ contela tu grande amor,/ y con no visto rigor,/ manifestado en sus ojos, respondió [...] que no esperes su favor» (vv. 829-834). Pero nada parece derrotar la esperanza del monarca, aunque dice saber «que no es justa cosa,/ ni para mi estado honrosa», casarme yo con quien sé/ que tiene en otro su fe/ y que es conmigo

13 Puede verse en la atención que se le dedica, por ejemplo, en el Instituto Max Planck para el Desarrollo Humano de Berlín. Véase al respecto, Frevert [2014]. 
engañosa» (vv. 880-884). La solución que idea el rey es una serie de añagazas para que la dama olvide a su caballero: la primera será fingir que don Juan se ha casado con la bella y rica madama Clavela (v. 911) pero, si aun así Armesinda no se doblegase a quererle, la siguiente mentira sería darle la fatal noticia de que su amado ha muerto en batalla (v. 902). Será don Carlos el encargado de llevar las malas nuevas. Sin embargo, el monarca, que había dudado de la fidelidad femenina al inicio de la jornada: «Mas no pierdo la esperanza,/ que de mujer la mudanza/ nunca desechada ha sido» (vv. 836$838)$, verá que el tópico no se cumple.

Continúa en esta $2^{\text {a }}$ jornada la demostración de la firmeza en la amistad por parte de don Carlos hacia don Juan y ocupa más versos que nunca. Forzado por el rey que maquina el plan para vencer la resistencia de la dama, encarga a don Juan ejecutarlo, por lo que le pone en un serio aprieto. Son varios los momentos en que aflora el dolor en su boca, siempre en apartes que se mezclan con los planes terribles que expone el rey: «iAy, pobre don Juan, ausente!» (v. 915). Y siente la doble obligación de amistad y vasallaje: «¡Sabe Dios lo que yo siento/ hacer de darla esta pena!/ Mas ¿qué he de hacer? La amistad/ y la obediencia me fuerzan» (vv. 1016-1019). Podríamos, por tanto, hablar también de una firmeza en el vasallaje, que lleva a don Carlos a tener que seguir la voluntad del rey y ser el encargado de transmitir a Armesinda las maquinaciones que el monarca ha inventado para doblegar su voluntad. Su situación interior lucha al tener que responder ante esos 'dos señores': el vasallaje y la amistad, y a llevar malamente la situación.

Pero, sin duda, es Armesinda la que tiene una ocasión excepcional para manifestar su firmeza en el amor, por encima de cualquier circunstancia. En primer lugar, porque espera desde hace seis meses alguna carta de don Juan sin que le llegue y necesitaría ese consuelo por la situación en que se encuentra, especialmente delicada: «haciendo yo resistencia/ a los intentos del rey,/ despreciando su grandeza,/ no mujer, sino diamante,/ firme roca, no veleta,/ y siendo a tan grandes olas/ inmóvil risco en firmeza. (vv. 990-996), pero no encuentra sino olvido. Tras oír el discurso de Carlos en que le da cuenta de la mentira urdida por el rey: la boda de don Juan. Las palabras de Armesinda la muestran hundida por completo y a punto de abandonar su fidelidad al amado ausente. En una larga alegoría con el efecto del fuego en las minas, la dama baja a su realidad y expresa su situación moral:

Así yo del mismo modo, contra cuya fortaleza ni los combates del tiempo, 


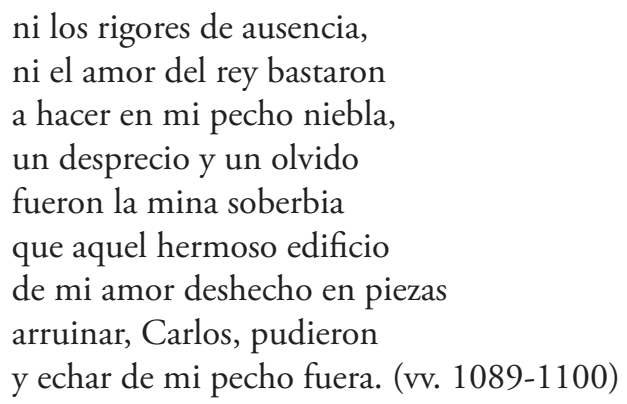

A pesar de lo sucedido, la dama se muestra firme en no ceder ante el rey. Una vez sola en escena, entona un soliloquio en el que lleva el tópico de la mudanza atribuido a la mujer hacia el varón: «Válgame Dios lo que yerra/ la que fía de quien tiene/ tan varia naturaleza/ como en el hombre se ve» (vv. 1162-1165). E insiste: «Mal ha dicho quien ha dicho/ que la mudanza se engendra/ solamente en las mujeres/ por su femenil flaqueza» (vv. 1169-1172). La dramaturga manifiesta en este momento su bagaje cultural citando a otras grandes resistentes del mundo clásico: «Artemisa y Julia,/ Annia romana y Pantea/ Lecostene, Porcia y Aria,/ Isicratea y Valeria» (vv. 1177-1180) y aun las sobrepuja: «y bien puedo yo contarme/ por más constante que estas,/ pues amo, mas sin tener/ las obligaciones que ellas» (vv. 1181-1184). Con todo, no piensa admitir a Filiberto y se plantea dos posibles soluciones: la primera, que desechará rápidamente, será entrar en religión (v. 1205). La protagonista parece inclinarse por provocar un desenlace fatal: «Ninguna cosa me cuadra/ ni me deja satisfecha,/ si no es morir, que el morir/ todas las cosas remedia» (vv. 1209-2212). Y no será la última vez que se presente el suicidio como una solución posible para poner fin al sufrimiento, aunque, tras meditarlo más, determine que es «bárbara locura»:

¿Qué haré? que estoy dudosa,

sin que pueda cuadrarme alguna cosa

que traiga mi remedio;

pues poner tierra en medio

no es a mi estado honesto conveniente,

ni tampoco que intente,

que es bárbara locura,

el darme con mis manos muerte dura. (vv. 1601-1608) 
Otra consideración de la protagonista interesa en esta $2^{a}$ jornada y es el desarrollo conceptual que realiza la autora, por boca de la protagonista, a propósito de la virginidad. Afirma Armensinda: «Si el honor me debiera [don Juan],/ yo la homicida de mí misma fuera» (vv. 1567-1568), para declarar a continuación que no es el caso, pues ha preservado su honra los seis años en que ha durado su relación. A partir de este hecho concreto, interesa la afirmación general que hace: «que es muy necia la que antes de himeneo/ cumple al hombre su antojo o su deseo» (vv. 1775-1776). Las razones que esgrime para esta afirmación son que el propio marido podría dudar de ella tras la boda: «porque después, en ocasión de esposo,/ de su lealtad viene a vivir dudoso,/ presumiendo muy loco y arrogante/ que los que a él se le hicieron siendo amante/ gozará otro en dulcísimos despojos» (vv. 1577-1581). Pocas veces se encuentra en la comedia una expresión tan explícita del motivo por el que las mujeres guardan su virginidad antes del matrimonio. Ni siquiera son las razones morales vinculadas a la práctica religiosa las que esgrime Leonor de la Cueva a través de su protagonista, sino el propio honor femenino. Resulta, en ese sentido, una interesante reivindicación. Sin duda, en la "comunidad emocional», tal como la define Barbara Rosenwein (2006), y centrándonos en el Barroco, la pérdida de la virginidad en la mujer le afectaba en primer lugar a ella, pero también a todo su ámbito social.

$\mathrm{Y}$, en medio de esta guerra de sentimientos, vuelve a mitad de la jornada la referencia a la guerra contra los franceses. Además de ensalzar a don Juan a través del sobrepujamiento que hacen sus soldados «No te igualan ¡pesia tal!» (v. 1220) respecto a César, Pompeyo romano, Escipión, el bravo africano y Aníbal de Cartago (vv. 12221224), su valor le hace ser «el mismo Marte» (v. 1218). También en este pasaje hay resonancias históricas, como son el premio que el capitán va a pedir al rey Fernando para sus soldados (vv. 1229-1232) y la noticia que le ha llegado a través de un espía de que el propio rey francés avanza por mar hacia Sicilia y que se debe impedir su arribo (vv. 1245-1248). Pero se trata de un breve fragmento de menos de cincuenta versos que sitúa de nuevo la acción en unas coordenadas históricas, da verosimilitud al conjunto y permite exaltar el valor militar del protagonista.

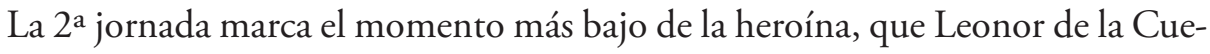
va sintetiza en pocos versos en los que da cuenta de la situación en que se encuentra: «Don Juan, traidor, casado;/ el rey de mis desdenes enojado;/ la infanta desabrida;/ y yo de todos tres aborrecida» (vv. 1501-1594). Nada puede ir a peor y la $3^{a}$ jornada tendrá, necesariamente, que marcar un cambio.

El último acto presenta la demostración de emociones por parte de los cuatro principales protagonistas de la obra: Armesinda, desde luego, pero también el rey 
seductor, su enamorado don Juan y Carlos, el amigo fiel. Este acto incorpora mayor número de escenas vinculadas a la guerra en Italia, pues contiene la marcha de don Juan y sus soldados hacia Nápoles de regreso de la batalla (vv. 1613-1676), el aviso de la vuelta de don Juan (vv. 1677-1683), su llegada misma (vv. 2133-2153), la naración detallada que hace de la batalla del río Garellano y la huida de los franceses (vv. 2154-2373), para terminar con el premio que recibe por su hazańa guerrera, que es la mano de su amada Armesinda (vv. 2374-2383). Por tanto, la autora presenta el final feliz de la comedia como premio a la victoria militar de don Juan y a la firmeza mantenida en el amor por los protagonistas. Además, soluciona la lujuria del rey con lo que podríamos ver como un caso de deus ex machina, en cuanto que el rey francés premia al monarca espańol con la mano de su hermana, la bella madama Blanca, y Filiberto lo acepta sin transición desde su capricho por Armesinda, quizá un amor nacido de los celos de su rival amoroso.

Pero antes de llegar a esta solución conveniente, observemos cómo se manifiestan las tres firmezas en esta última jornada. Si la firmeza en la amistad de don Juan por don Carlos protagonizaba la segunda jornada, aquí lo va a hacer la constancia en el amor de Armesinda. A pesar del año y medio transcurrido desde que se fue su amado a la guerra, no ha recibido cartas suyas -el rey se las ha requisado a don Juan- y se queja ante Leonor del olvido al que la ha sometido su amado y del matrimonio que cree que ha contraído con Clavela. El largo parlamento de más de sesenta versos que pronuncia hace posible que se eleve el caso particular a general, y presente al público una serie de consideraciones de gran calado sobre la sicología masculina y la ruptura de los tópicos en torno a la mujer. En concreto, se lamenta de que no hay pruebas de que don Juan haya mantenido su correspondencia amorosa "cuando yo, siendo mujer/ desmintiendo mi flaqueza,/ resisto a tanta grandeza/ y burlo tanto poder» (vv. 1752-1755), de lo que desprende que «No hay en los hombres verdad./ Miente, Leonor, quien dijere/ que a la mujer se prefiere/ en firmeza y en lealtad» (vv. 1760-1763). Sigue una secuencia narrativa en la que Armesinda detalla el proceso de seducción que aplican los hombres a las mujeres: «Pretende el galán la dama/ que le ha parecido bien,/ y conquista su desdén/ bien a costa de su fama» (vv. 1764-1767), para de nuevo incidir en los desastres que trae la pérdida de la honra si ella cede a su pasión violenta: «Ella, incauta y obligada/ del amante cauteloso,/ le hace dueño venturoso/ de la prenda más preciada» (vv. 1776-1779). Lo que sucede luego es que el varón que ha deshonrado a la mujer se disculpará de guardarla fidelidad con la excusa de que, si la dama cedió con él, puede haberlo hecho antes y lo hará después: 


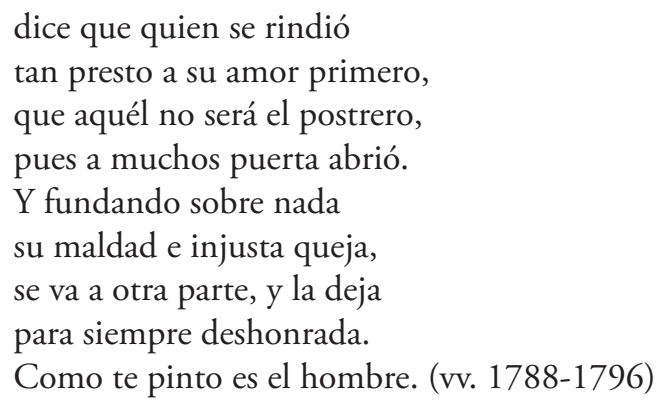

Incluso hablando entre sueños, Armesinda va a manifestarse fiel a su amor por don Juan y despreciativa hacia el rey que la corteja (vv. 1856-1890). Cuando despierta, recuerda el sueńo y su actitud: "Con mi ingrato me sońaba/ como si fuera verdad,/ y de mi mucha lealtad/ satisfacciones le daba» (vv. 1924-1927), que tiene ecos del calderoniano «no se pierde/ obrar bien, aun entre sueños» (vv. 2400-2401), con el que Segismundo reflexiona ante Clotaldo en La vida es sueño. Intercala en la declaración de sus sueños la conversación que tuvo con don Juan y las dudas que este expuso sobre la naturaleza de la mujer: "Prosiguió: siendo mujer,/ es cierto te rendirás/ y mi amor olvidarás» (vv. 1949-1942), a lo que ella replica: «de mi fe no he de mudarme» (v. 1946). Don Carlos interrumpe la escena con importantes noticias, para tratar - de parte del rey- de hacer tambalear la firmeza de Armesinda. Y son, ni más ni menos, que la muerte en batalla de don Juan (vv. 1997-1999). La noticia hace que Armesinda, rota de dolor, recorra el itinerario de su vida: su llegada a palacio como dama de Leonor, su amor correspondido por don Juan de Gayazo durante seis años, la marcha de su amado a la guerra por imperativo del rey, su boda allí con otra dama, el olvido de don Juan de su primer amor y la constancia que ella mantuvo a pesar de las circunstancias, incapaz de aceptar las pretensiones del rey:

mas como el gusto faltaba, ni promesas de ser reina, ni ruegos de Celidaura, ni razones de don Carlos, ni ofensas tan declaradas, ni el hallarme aborrecida y tan sola y desdichada, bastó a mi constante pecho para que hiciese mudanza. (vv. 2061-2069) 
Finalmente, el hecho de ser conocedora de la muerte de su amado la hace afirmar su decisión de "acabar en un convento/ las penas que aquí me acaban» (vv. 2086-2087), para lo que pide permiso al rey presionándole en dos versos: ${ }_{i} \mathrm{O}$ has de hacer lo que te pido,/ o matarme con tu espada!» (vv. 2108-2109). El comentario de los que escuchan estas palabras es alabar su actitud:

$\begin{array}{ll}\text { Rey } & (A p .) \text { iHay semejante mujer! } \\ & \text { Callen griegas y romanas. } \\ \text { INFANTA } & (A p .) \text { Por demás es porfiar. } \\ \text { CARLos } & (A p .) \text { iQué firmeza tan extraña! } \\ & \text { ¡Dichoso don Juan mil veces! } \\ \text { LeONElo } & \text { Todos, admirados, callan. (vv. 2110-2115) }\end{array}$

Pero el rey trata de forzarla y ella reacciona: «Dareme mil puñaladas/ antes que este intento mude» (vv. 2131-2132). La tensa escena se interrumpe por la llegada de don Juan, Tristán y los guerreros. Estoy de acuerdo con Scott Soufas cuando apunta

Armesinda's uniquenesses as a dramatic component in this play is emphasized not only throught the frequent references to her as an atypical woman, impervious to the temptations of material wealth and resistant to impulse for revenge, but also in the sense that she occupies an exceptional spatial dimension within the dramatized physical architecture of Filiberto's palace and the portrayed social space of a woman alone. [Scott Soufas, 2000: 151]

La solución para los enamorados llegará ya al final de la $3^{\text {a }}$ jornada y no como esperaríamos en una obra en la que su protagonista ha mantenido el pulso por su virginidad tanto en los seis años de amor con su prometido como en el año y medio en que le enviaron a la guerra y el rey trató de seducirla. Porque, frente a un posible desenlace en la modernidad, las fuertes palabras que Armesinda dirige al rey durante la obra no son las que van a hacer que este ceje en su empeño. No participamos en nuestra época del mismo 'régimen emocional', en palabras de William Reddy, porque es muy distinto «el conjunto de emociones normativas y de rituales oficiales, prácticas y 'emotives' que expresan y se nos inculcan; un fundamento necesario de cualquier régimen político estable» [Reddy, 2001: 129]. Por 'emotive', Reddy entiende el privilegio de la palabra frente a otras manifestaciones como el llanto o la sonrisa. El fuerte sufrimiento emocional que experimenta Armesinda por el conflicto objetivo de su amor a don Juan y la necesidad vital de no ofrecer oposición al acoso del rey, le dejaba 
muy poco espacio para la libertad emocional, como no fuera el de la palabra y esa aún, con mucho riesgo. De forma extraordinaria, Leonor de la Cueva presenta a su protagonista como dueña de su lenguaje en un mundo de hombres y, en el caso del rey, de hombres con una superioridad moral y social apabullante. Podríamos preguntarnos si esa libertad de palabra responde a un hecho presente en la sociedad del siglo XVII y hemos de responder que, como tantas situaciones que presenta el teatro, no existe esa correlación entre el binomio vida/teatro. Pero, al menos, la obra dramática instaura un espacio de libertad oral, que adelanta en siglos lo que serán reivindicaciones que lleguen al fin que se pretende.

Si las declaraciones de Armesinda no hacen cambiar de opinión al rey, que sigue acosándola, como se ha visto, tampoco lo logrará su declaración de huir a un convento ni siquiera la decisión que manifiesta de suicidarse. El lujurioso rey solo soltará a su presa cuando don Juan llegue como deus ex machina con una oferta más conveniente desde el punto de vista político: el ofrecimiento por parte del rey de Francia de su propia hermana, madama Blanca, para que case con el rey de España y lleguen las paces (vv. 2358-2361), lo cual, desde luego, no responde a ningún hecho histórico. Se desvía aquí notoriamente Leonor de la Cueva de la trabazón histórica que era el sustrato de su comedia y, como buenos oidores, deberíamos preguntarnos el porqué. Quizá sea cierto, como señaló Parker Aronson, que

Women -Armesinda an the Princesses Celidaura and Blanca- continue to be sexual pawns which men may barter to their advantage, thereby suggesting that women's influence and persuasion is illusory and Cueva's drama is perhaps more real than we would like to imagine. [Parker Aronson, 2007: 151]

Pero la lucha de Armesinda por conservar su honestidad, no merecía que quedara como una dama 'suelta' -sin esposo-, por lo que don Juan, que llega victorioso y triunfante ante el rey Filiberto, pide la mano de Armesinda para sí mismo (vv. 2381-2383), lo cual acepta sin dudar el monarca (vv. 2392-2393). La declaración del rey -aunque en aparte- parecería dejarle en el mejor lugar posible, tras sus fatales actuaciones anteriores, y devuelve esta comedia a las que podrían incluirse en el tipo speculum principis. El monarca declara:

(Ap.) Hoy aumento mis victorias

con ganar la de mí propio,

que esto es ser rey y cumplir

con el título que gozo, 


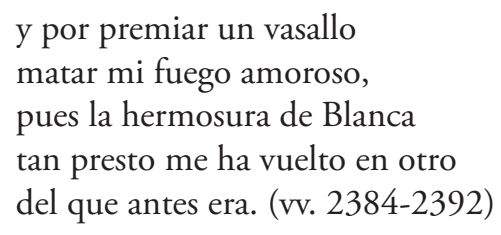

Lo que Leonor de la Cueva no le hace decir en ningún momento es la verdadera razón de su aparentemente caprichoso cambio, pues no es aumentar sus victorias venciéndose a sí mismo -aunque lo asevera- ni cumplir con lo que se esperaría de su figura real -que también lo enuncia como motivo del cambio- ni matar su fuego amoroso para premiar a un vasallo que lo merece -tercera razón que esgrime-, ni siquiera la belleza de la nueva dama -cuarta razón que se da- sino una mucho más baja y que en ningún momento se atreve a expresar la escritora, aunque a buen entendedor pocas palabras bastan: el interés político. Y aunque no se ponga en boca del monarca, demasiado desdoro sería, sus espectadores entendieron perfectamente la lección. Quizá haya que rebatir la afirmación de Parker Aronson de que la obra no llega a presentar una reivindicación que sería esperable pasadas unas centurias. Porque situada en su tiempo, el lector atento sabe leer que en el Siglo de Oro se dice sin decir, se trata de una pedagogía para reyes, en palabras que juegan con las de Carmen Sanz Ayán [2006] y los hechos dejan clara la enseñanza sin necesidad de más explicaciones. Imposible, desde luego, pensar que la resistencia de una mujer iba a vencer la lujuria de un rey en el Siglo de Oro, pero ya es bastante humillación para la monarquía presentar a un rey que solo vencerá su pasión cuando triunfe sobre él el ansia de ganancia política.

A los tres matrimonios anunciados se suma para acabar la comedia, motu proprio, el criado Tristán, que, si no tuvo un papel determinante en esta comedia, como sí ocurría en otras de su tiempo, sin embargo, cierra con un guiño de comicidad la acción de la misma:

\footnotetext{
Nadie trata de Tristán, y ¡vive Dios, que yo solo he muerto más enemigos que un boticario tramposo, ni que un médico moderno!
} 
El Rey le promete una alcaidía (v. 2423) y Leonor se nombra su esposa sin necesidad de más intermediarios ni protocolo (v. 2429). La comedia termina con el consabido parlamento de captatio benevolentiae del gracioso:

\author{
Y aquí se acaba, senado, \\ perdonad mi estilo tosco, \\ La firmeza en el ausencia \\ cuyos yerros son notorios. (vv. 2430-2433)
}

En la última parte de la obra se anuncian fiestas en las bodas del rey y madama Blanca, que traerán la paz con Francia (vv. 2412-2413). De este modo, la obra termina en estructura circular como empezó, con fiestas en la corte de Nápoles, si bien las del inicio están muy desarrolladas y son un verdadero torneo de máscaras con "galas, letras e invenciones» (v. 18), para festejar el cumpleaños del rey, que pretende ya a Armesinda. Participan en él cinco caballeros de la nobleza, incluido el protagonista don Juan, que será quien gane el torneo y, en teoría, consiga la mano de la dama, si no fuera porque justo tras acabar la máscara llega el escrito del rey enviándole a la guerra, para separarlo de su amada.

Muchas otras cuestiones podrían observarse en esta comedia tan lograda, como es el juego epistolar. En efecto, no son pocas las cartas que se mueven con mensajes importantes. Hemos hecho referencia a la que trae la orden del rey que envía a don Juan a la guerra para separarlo de Armesinda y dejarle el camino libre hacia la dama (v. 150) -será la única escrita en prosa, como corresponde a su contenido-. Sigue la que escribe don Juan a su amada advirtiéndole del caso (v. 209) y ella recibe extrañada mientras dice que en seis años de amor es la primera vez que su amado la escribe (vv. 381-384). La $2^{\text {a }}$ jornada comienza haciendo una referencia a una carta enviada por el rey a Armesinda, se supone que dándole a conocer sus amores, en una escena en la que el rey interroga a don Carlos por la reacción de la dama al recibirla (v. 825). La respuesta, oral en este caso, corta todas las esperanzas al rey (v. 834). Todavía en esta jornada hay dos cartas más que trae Tristán en mano a don Juan: la de don Carlos (v. 1314) en que da fe de la fidelidad que le guarda su amada y la de Armesinda (v. 1315) que le refiere el intento de seducción del rey y su firmeza para rechazarle hasta la misma muerte. La $3^{\mathrm{a}}$ jornada en relación con el intercambio epistolar solo trae la referencia de don Juan a que su amigo Carlos le asegura en diversas cartas la correspondencia amorosa de Armesinda en su ausencia (v. 1655), las palabras del rey en que declara que requisa las cartas de don Juan dirigidas a la dama (vv. 1692-1694) y las 
quejas de Armesinda de que desde que se fue su amado a la guerra hace año y medio, no ha recibido ni una letra suya (v. 1749). Por todo lo dicho, se puede observar el importante lugar que tienen las cartas en esta comedia, pues transmiten órdenes, dan cuenta de los sentimientos de los enamorados y sufren el ser requisadas por quien tiene poner para hacerlo. Nada de esto, sin embargo, es óbice para aplacar el amor de la pareja principal. En realidad, toda esta contribución podría haberse elaborado haciéndola girar en torno a estas cartas, lo suficientemente expresivas del desarrollo de la acción y de los sentimientos de los personajes que protagonizan la comedia. Sin embargo, alguna de las 'firmezas' que se han tratado, hubieran quedado quizá más veladas si se hubiera contado solo con la correspondencia epistolar. Pero conviene tener en cuenta que las cartas funcionan como colaboradoras muy interesantes en la acción, completan pasajes y hechos clave de la misma y filtran en lenguaje directo las emociones de los corresponsales.

Cuando Monique Scheer habla sobre las 'prácticas emocionales', se pregunta de qué manera los historiadores de las emociones trabajan con las fuentes: «Cómo vamos a saber lo que la gente 'realmente' sentía si mantenían esa sensación para sí mismos y no dejaron ningún registro histórico? [...] ¿Debemos suponer que las fuentes documentan la falta de honradez o incluso la negación? [al no incluir las emociones]» $Y$ responde que es necesario consultar una amplia gama de fuentes para confirmar si la emoción esperada se encuentra o no en ellas. Su ausencia reiterada podría llevar a considerar esa emoción ausente [Scheer, 2012: 219]. Pero como se ha podido ver durante esta exposición, el teatro puede ser también un excelente canal para conocer qué emociones imperan en un momento determinado, aun siendo conscientes de que las situaciones y las causas que provocan determinadas emociones varían con el paso del tiempo [Plamper, 2014: 23]. También la 'firmeza' como cualidad moral, traspuesta en materia literaria por una mujer culta de mitad del siglo XVII, es capaz de establecer un diálogo con diversas comunidades emocionales, ya sean sincrónicas o diacrónicas. 


\section{BibLIOGRAFÍA}

Calderón de la Barca, Pedro [1998]: La vida es sueño, ed. Evangelina Rodríguez Cuadros, Madrid, Austral, $20^{\mathrm{a}}$ ed.

Doménech, Fernando, y Felicidad González Santamera, ed. [1994]: Teatro de mujeres del Barroco, Madrid, Publicaciones de la ADE. (Serie: Literatura dramática, $\left.n^{\circ} 34\right)$.

Febvre, Lucien [1941]: «La sensibilité et l'histoire: Comment reconstituer lavie affective d'autrefois?», Annales d'histoire sociale, 3, pp. 5-20.

Frevert, Ute [2014]: «The Modern History of Emotions: a Research Center in Berlin», Cuadernos de Historia Contemporánea, 36, pp. 31-55.

Gavela García, Delia, ed. [2010]: Agustín Moreto, De fuera vendrá quien de casa nos echará, en Comedias de Agustín Moreto. Primera Parte de comedias, dir. María Luisa Lobato; coord. Judith Farré Vidal, Kassel, Reichenberger, vol. II, pp. 1-179.

González Santamera, Felicidad [2000]: «Leonor de la Cueva y Silva, una escritora ausente», en Luciano García Lorenzo (ed.), Autoras y actrices en la historia del teatro español, Murcia, Servicio de Publicaciones, pp. 47-80.

Pampler, Jan [2014]: «Historia de las emociones: caminos y retos», Cuadernos de Historia Contemporánea, 36, pp. 17-29.

Parker Aronson, Stacey L. [2007]: «The Threat of Rape in Leonor de la Cueva's La firmeza en la ausencia», Romance Notes, 47, 2, pp. 141-152.

Reddy, William [2001]: The Navigation of Feeling: A Framework for the History of Emotions, Cambridge, Cambrige University Press.

Rosenwein, Barbara [2006]: Emotional Communities in the Early Midle Ages, Ithaca, N.Y., Cornell University Press.

SÁnchez Jiménez, Antonio [2015]: «Lope de Vega contra los leguleyos: el soneto epitafio a Don Francisco de la Cueva (1628) y su contexto», Atalanta. Revista de las Letras Barrocas, 3 (1), 29-52.

SAnZ Ayán, Carmen [2006]: Pedagogía de reyes: El teatro palaciego en el reinado de Carlos II, Madrid, Real Academia de la Historia.

Scheer, Monique [2012]: «Are emotions a kind of practice (and is that what makes them have a history)? A Bourdieuian approach to understanding emotion", History and Theory, 51, 2, pp. 193-220.

Scott Soufas, Teresa, ed. [1997]: Women's Acts. Plays by Women Dramatists of Spain's Golden Lexington, UP of Kentucky, pp. 195-224. 
- [2000]: «The absence of desire in Leonor de la Cueva's La firmeza en la ausencia [Loyalty in absence], en Gender, Identity, and Representation in Spain's Golden Age, Lewisburg, Bucknell University Press/London, Associated University Presses, 2000, pp. 142-155.

Serrano y Sanz, Manuel, Apuntes para una biblioteca de escritoras españolas: desde el año 1401 al 1833, Madrid, Sucesores de Rivadeneyra, 1903.

Sullivan, Henry W., «Law, Desire, and the Double Plot: Toward a Psychoanalytic Poetics of the Comedia', en The Golden Age 'Comedia': Text, Theory, and Performance; ed. Charles Ganelin y Howard Mancing, West Lafayette, Purdue UP, 1994, pp. 222-235.

Vega, Lope de [2007]: Laurel de Apolo, ed. Antonio Carreño, Madrid, Cátedra.

Voros, Sharon D., «Leonor's Library: The Last Will and Testament of Leonor de la Cueva y Silva", Hispanic Studies in Honor of Robert L. Fiore, ed. Chad M. Gasta y Julia Domínguez, Newark, Juan de la Cuesta, 2009, pp. 497-510. 